\title{
Perilaku Bias Dalam Menentukan Keputusan Investasi
}

\author{
Tiar Lina Situngkir ${ }^{1}$, Nugraha ${ }^{2}$, Disman $^{3}$ \\ Universitas Singaperbangsa Karawang ${ }^{1}$, Universitas Pendidikan Indonesia ${ }^{1,2,3}$ \\ email korespondensi: tiarlina.situngkir@fe.unsika.ac.id
}

\begin{abstract}
Abstrak: Erroneous decisions will have an impact on the results, so this study aims to examine how investment decisions are Affected by some biased behavior by investors. This study uses primary data collected from questionnaires filled in by 161 responses whose subjects are the academic community of Universitas Singaperbangsa Karawang. The method used is purposive sampling. The analysis technique used is the moderated regression analysis. The findings of this study indicate that the bias behavior of investors, which is represented by excessive self-confidence and confirmation bias, influences in determining the investment decisions taken, sharpened by the moderating variable of gender which provides information that has a significant effect on excessive confidence in investors. The implication that can be useful for investors is to be more careful in their information and still see accurate data in determining investment decisions.
\end{abstract}

Kata kunci: overconfidence, confirmation bias, gender, investment decision

Dengan semakin bertumbuh dan berkembang dunia keuangan, membuat investor semakin mudah untuk melakukan investasi. Keputusan investasi merupakan kegiatan yang dilakukan investor dengan tujuan mendapatkan imbal hasil dimasa depan. Banyak faktor yang memberi pengaruh dalam menentukan keputusan investasi. Investor sebagai orang yang memiliki peranan penting perlu memperhatikan beberapa data dan informasi yang tersedia sehingga keputusan yang dihasilkan memberikan hasil yang maksimal. (Pertiwi, P. J.,dkk, 2016)

Teori Hipotesa Pasar Efisien yang menjelaskan bahwa pasar merupakan suatu tempat dengan segala informasi yang lengkap dan semua dianggap telah menerima informaSsi yang sama.(Fama, 1970) Namun kenyataan yang terjadi di pasar, kadang kala terjadi perubahan dan respon pasar tidak sesuai dengan yang diharapkan. Maka kejadian anomali ini memicu para peneliti terdahulu melakukan penelilitian lebih dalam yang diinisiasi (A. T. and D. Kahneman, 1974). Beliau memaparkan penilaian Ketika situasi tidak pasti kemungkinan menghasilkan heuristik atau bias. Dilanjutkan (Kahneman \& Tversky, 1979) dengan teori prospek dan dilanjutkan dengan pada tahun 1992 tentang Teori prospek Lanjutan yang membahas mengenai tiga fungsi yaitu perihal mental accouting untuk mendapatkan dampak framing (framing effect); fungsi nilai (value function) menyatakan fungsi utilitas yang mendefinisikan laba (gain) dan rugi (losses) serta fungsi penimbang probabilitas (probability weighting function).

Maka secara rasional investor menggunakan segala informasi dan data yang tersedia untuk menentukan keputusan investasi yang paling tepat. (Fama, 1970) Namun kadang sebagai manusia ada pengaruh psikologi yang terdampak pada keputusan yang dilakukan. Dampak dari pengaruh psikologi, yaitu bias turut berperan pada saat investor melakupan keputusan investasi. Teori perilaku keuangan menjelaskan 
ada anomali kadang kala terjadi pada perilaku investor yang dikenal sebagai perilaku bias yang terbukti mempengaruhi keputusan investasi. (Nofsinger, 2018; Pompian, 2012; Ritter, 2003).

Kepercayaan diri yang berlebihan adalah bias yang paling dominan pada teori keuangan perilaku. Kepercayaan diri yang berlebihan adalah perilaku yang merasa diri memilki kompetensi yang mumpuni sehingga sering mengabaikan situasi dan kondisi yang terkini. (Pompian, 2012) Kepercayaan diri yang berlebihan pada investor juga menunjukkan dirinya berada pada posisi diatas rata dalam keuangan sehingga mampu menentukan keputusan investasi dengan baik. (Trejos et al., 2019). Jelas, perilaku bias kepercayaan diri yang berlebihan memberikan dampak pada keputusan investasi. Kepercayaan diri yang berlebihan mengakibatkan keputusan investasi irasional yang berdampak buruk bahkan kegagalan. (Skała, 2008)(Thi \& Ngoc, 2014).

Bias Konfirmasi merupakan perilaku bias yang masih kurang digali dampaknya pada teori perilaku keuangan. (Costa et al., 2017) menjadi salah satu alasan untuk meneliti bias ini dalam memberi kontribusi pada keputusan investasi. Beberapa penelitian terdahulu memberikan informasi bahwa bias konfirmasi mempengaruhi keputusan investasi. (Sulistiawan, 2015) Bias konfirmasi adalah perilaku bias yang menjelaskan bahwa seorang investor hanya mengakomodasi atau mengkonfirmasi informasi yang sesuai dengan persepsi atau pendapat yang sesuai dengan pendapat yang dibutuhkannya. Informasi yang tidak sesuai dengan konfirmasi dan pendapat yang dibutuhkan investor tidak diterima.(Nofsinger, 2018; Pompian, 2012)

Beberapa penelitian yang telah dilakukan menyatakan beberapa perilaku bias terbukti mempengaruhi keputusan investasi. Penelitian yang dilakukan oleh (Budiarto, 2017) meneliti pengaruh literasi keuanga, kepercayaan diri berlebihan, penghindaran penyesalan, dan toleransi risiko terhadap keputusan investasi. Kemudian penelitian yang dilakukan (Waiqotul, 2017) menganalisa suku bunga dan kepercayaan diri berlebihan terhadap keputusan investasi. Selanjutnya penelitian (Wulandari \& Iramani, 2014) menganallisa pengalaman penyesalan, toleransi risiko, kepercayaan diri berlebihan, pandangan risiko, terhadap keputusan investasi dosen ekonomi.

Berdasarkan dari penelitian terdahulu, penelitian ini menggunakan kedua perilaku bias kepercayaan diri yang berlebihan dan bias konfirmasi sebagai variabel bebas dan untuk mempertajam pengaruh dari variabel bebas tersebut, ditambahkan variabel moderasi yaitu jenis kelamin dalam mempengaruhi keputusan investasi. Penelitian ini bertujuan menginvestigasi dampak dari perilaku bias kepercayaan diri berlebihan dan bias konfirmasi dengan interaksi dengan jenis kelamin terhadap keputusan investasi. 


\section{METODE}

Penelitian ini menggunakan pendekatan kuantitatif. Data yang digunakan adalah data primer yang dikumpulkan dengan menggunakan kuisioner. Kuisioner dibuat menggunakan google form, dan disebarkan melalui grup watsapp yang berada di lingkungan civitas akademika Universitas Singaperbangsa Karawang. Responden yang terkumpul berjumlah 161.

Teknik analisa penelitian ini menggunakan analisa metode regresi dengan perangkat lunak SPSS versi 21 dengan alat tambahan process, yang bermanfaaat untuk mengolah data yang memiliki variabel moderasi. Dengan metode ini akan menganalisa bagaimana perilaku bias kepercayaan diri berlebihan dan bias konfirmasi berinteraksi dengan jenis kelamin sebagai moderasi mempengaruhi keputusan investasi.

Kerangka pemikiran dari penelitian ini adalah sebagai berikut:

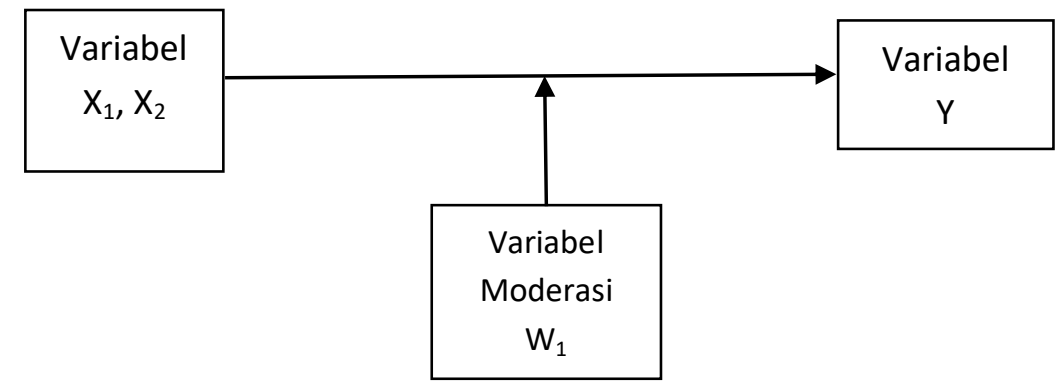

\section{Gambar 1: Kerangka Pemikiran}

Variabel $X$ adalah variabel independent yang terdiri dari $X_{1}$ yaitu kepercayaan diri berlebihan, variabel $X_{2}$ yaitu bias konfirmasi, dan $W_{1}$ adalah variabel moderasi yaitu jenis kelamin, sedangkan Variabel $Y$ adalah variabel dependen yaitu keputusan investasi.

Dari kerangka pemikiran tujuan penelitian untuk mengetahui apakah ada pengaruh signifikan dari variabel $X_{1}$ dan $X_{2}$ terhadap $Y$, dan apakah ada interaksi variabel $W_{1}$ dalam mempertajam variabel $X_{1}$ dan $X_{2}$ dalam mempengaruhi keputusan investasi.

\section{HASIL}

Dari hasil analisa statistik deskripsi terlihat bahwa secara sebaran jawaban, semua responden menjawab pertanyaan variabel kepercayaan diri berlebihan dan bias konfirmasi mencakup pilihan paling rendah 1 dan paling tinggi 5 dengan masing-masing standasr deviasi untuk kepercayaan diri berlebihan adalah 0.69 dan bias konfirmasi adalah 0.71 . Dengan standar rata masing-masing jawaban adalah 3.8 untuk variabel kepercayaan diri berlebihan dan 3.7 untuk bias konfirmasi. Disajikan seperti tabel dibawah ini. 
Tabel : Statistik Deskriptif.

\begin{tabular}{lcccc}
\hline Keterangan & Minimum & Maksimum & Rata-Rata & $\begin{array}{r}\text { Standar } \\
\text { Deviasi }\end{array}$ \\
\hline $\begin{array}{l}\text { Kepercayaan diri } \\
\text { berlebihan }\end{array}$ & 1 & 5 & 3.8 & 0.69 \\
\hline Bias Konfirmasi & 1 & 5 & 3.7 & 0.71
\end{tabular}

Data: Sumber diolah

Untuk data hasil unduh kusioner telah dilakukan uji normalitas dengan menggunakan uji kenormalan Kolmogorov-Smirnov nilai probabilita adalah 0.200 yang berarti lebih besar dari 5\% maka dapat disimpulkan bahwa residual menyebar normal.

Selanjutnya dari hasil regresi menampilkan bahwa kedua variabel perilaku bias kepercayaan diri berlebihan dan bias konfirmasi secara hasil anova yang nilai probabilitanya adalah 0.00. Secara parsial masingmasing variabel menghasilkan nilai probabilita senilai 0.032 untuk variabel kepercayaan diri berlebihan dan nilai probabilita 0.03 untuk variabel bias konfirmasi, Untuk nilai interaksi variabel jenis kelamin pada regresi ini adalah 0.026 untuk kepercayaan diri berlebihan dan 0.082 untuk bias konfrimasi. Seperti tabel berikut ini:

Tabel : Hasil Regresi Anova dan Koefisien

Keterangan Nilai Probabilita $(P)$ Anova Nilai $P$ Koefisien

Nilai interaksi

$\begin{array}{lll}\text { Kepercayaan diri } & 0.00 & 0.032\end{array}$

0.026

Berlebihan

Bias Konfirmasi

0.00

0.03

0.082

Data: Sumber diolah 
Merujuk hasil analisa diatas, dilihat dari tabel statistika responden menjawab semua pilihan dari minimum yaitu 1 dan maksimum yaitu 2 . Rata-rata nilai berada dipilihan bagian tengah ditunjukkan nilai 3.78 dan 3.8. Jenis kelamin lengkap terdiri dari pria dan wanita yang ditunjukkan dengan angka 1 untuk pria dan 2 wanita.

Penelitian ini membuktikan bahwa terjadi bias dari perilaku investor dalam menentukan keputusan, sesuai dengan teori perilaku keuangan yang menjelaskan terjadi bias dalam mempengaruhi keputusan investasi.(Pompian, 2012) Terbukti secara simultan kedua perilaku bias kepercayaan diri berlebihan dan bias konfirmasi menampilkan hasil nilai probabilita yang lebih kecil dari 5\%, yang bermakna memberi pengaruh terhadap keputusan investasi. Hasil ini sesuai dengan penelitian (Supramono \& Wandita, 2017) namun berbeda dengan hasil penelitian ...

Hasil nilai probabilita parsial dari kedua variabel independent menujukkan 0.032 pada variabel kepercayaan diri berlebihan, bermakna secara parsial keputusan investasi dipengaruh oleh bias kepercayaan diri berlebihan. (Ainia M, Nadya Septi Nur Lutfi, 2018) Demikian juga variabel bias konfirmasi menunjukkan nilai probabilitas 0.03 , bermakna secara parsial keputusan investasi dipengaruhi bias konfirmasi. Kedua nilai probabilitas masing-masing variabel independent dibawah 5\% berarti signifikan mempengaruhi variabel dependen. Hasil ini selaras dengan penelitian (Supramono, Wandita, 2017) (Park et al., 2012)

Nilai interaksi dari masing-masing variabel yaitu kepercayaan diri berlebihan dan bias konfirmasi adalah 0.026 dan 0.08 . Nilai ini menunjukkan jenis kelamin mempertajam pengaruh variabel kepercayaan diri berlebihan, (Nana, 2012) sedangkan pada bias konfirmasi jenis kelamin tidak mempertajam memberi pengaruh dalam menentukan keputusan investasi investor. Hasil ini sejalan dengan penelitian (Rahadjeng, 2011) (Supramono \& Wandita, 2017) (Nurvitasari \& Rita, 2020)

Penelitian ini berhasil membuktikan secara simultan dan secara parsial serta dipertajam dengan interaksi variabel moderasi jenis kelamin bahwa kepercayaan diri berlebihan dipertajam dengan jenis kelamin memberi pengaruh pada keputusan investasi. Hasil ini menambah keyakinan bahwa jenis kelamin memberi interkasi tajam pada hasil keputusan investasi. Penelitian terdahulu membuktikan jenis kelamin pria menampilkan kepercayaan diri lebih tinggi dari wanita mengalami bias kepercayaan diri berlebihan. (Barber, BradM., 2001; Hassan et al., 2014)

Namun pada variabel bias konfirmasi, interaksi jenis kelamin tidak mempertajam interaksi pada keputusan investasi. Tidak tampak perbedaan Pria dan wanita yang signifikan dalam mempertajam pengaruh bias konfirmasi pada keputusan investasi.(Rahadjeng, 2011)(Nurvitasari \& Rita, 2020)

Penelitian ini masih terbatas meneliti dua perilaku bias dalam menentukan keputusan investasi, yaitu kepercayaan diri yang berlebihan dan bias konfirmasi, untuk selanjutnya alangkah baiknya jika ditambah 
variabel bebas yang diteliti, seperti bias penghindaran resiko, dan lain-lain. Demikian juga dengan faktor moderasi bisa ditambahkan dengan faktor demograpi lainnya seperti pendidikan dan lain lain (Farrell, 2014)(Kumar \& Goyal, 20s15) (Baker et al., 2019) Sehingga akan menambah kompleksitas dan konseptual pada teori perilaku keuangan.(Baker \& Filbeck, 2013)

\section{KESIMPULAN}

Penelitian ini menyimpulkan bahwa teori keuangan tradisional tidak mampu menjelaskan faktor anomali yang terjadi di pasar, yang dijelaskan oleh teori hipotesa pasar efisien bahwa dengan informasi yang lengkap memberi informasi yang efisien. (Fama, 1970) Namun dengan hadirnya teori perilaku keuangan memberikan ada faktor bias dalam mempengaruhi keputusan investasi investor (Pompian, 2012)

Hasil penelitian ini memberikan simpulan keputusan investasi investor terdampak perilaku bias kepercayaan diri berlebihan dan bias konfirmasi. Dan terbukti pada bias kepercayaan diri berlebihan faktor jenis kelamin mempertajam pengaruh tersebut pada keputusan investasi. Namun jenis kelamin tidak berinteraksi pada bias konfirmasi mempengaruhi investor menentukan keputusan investasi.

Hasil penelitian menjadi saran dan masukan bagi perusahaan keuangan untuk mempertimbangkan faktor bias dan jenis kelamin dalam membuat produk investasi. Sehingga bisa mengakomodasi dengan baik dan memberi keuntungan bagi perusahaan dan investor.

Untuk investor sebagai subyek yang menentukan keputusan investasi lebih bisa berhati-hati dalam bertindak. Berbagai data dan informasi bisa menjadi pertimbangan dalam menentukan keputusan investasi yang memberikan imbal hasil maksimal di masa depan.

Bagi para akademisi penelitian ini bisa menambah hasanah dan rujukan untuk penelitian berikutnya di bidang perilaku keuangan, dengan menambah variabel - variabel lain sebagai variabel independent, maupun moderasi. Dengan demikian akan menambah warna pada konsep dari hasil penelitian yang diterbitkan.

\section{DAFTAR PUSTAKA}

Ainia M, Nadya Septi Nur Lutfi, L. (2018). The influence of risk perception, risk tolerance, overconfidence, and loss aversion towards investment decision making. Journal of Economics, Business, \& Accountancy Ventura, 21((3)). https://doi.org/doi.org/10.14414/jebav.v21i3.1663

Baker, H. K., \& Filbeck, G. (2013). Portfolio Theory and Management. Portfolio Theory and Management, 1-20. https://doi.org/10.1093/acprof:oso/9780199829699.003.0001

Baker, H. K., Kumar, S., Goyal, N., \& Gaur, V. (2019). How financial literacy and demographic variables relate to behavioral biases. Managerial Finance, 45(1), 124-146. https://doi.org/10.1108/MF-012018-0003 
Barber, BradM., and T. O. (2001). Boys will be boys: Gender, overconfidence, and common stock investment. Quarterly Journal of Economics, 116:1, 261-292.

BUDIARTO, A. (2017). PENGARUH FINANCIAL LITERACY, OVERCONFIDENCE, REGRET AVERSION BIAS, DANRISK TOLERANCE TERHADAP KEPUTUSAN INVESTASI (Studi pada investor PT. Sucorinvest Central Gani Galeri Investasi BEI Universitas Negeri Surabaya). Jurnal IImu Manajemen (JIM), Vol 5,(No 2).

Costa, D. F., de Melo Carvalho, F., de Melo Moreira, B. C., \& do Prado, J. W. (2017). Bibliometric analysis on the association between behavioral finance and decision making with cognitive biases such as overconfidence, anchoring effect and confirmation bias. Scientometrics, 111(3), 1775-1799. https://doi.org/10.1007/s11192017-2371-5

Fama, E. F. (1970). (1970). Efficient capital markets: A review of theory and empirical work. The Journal of Finan, 25(2), 383-417. https://doi.org/http://dx.doi.org/10.1111/j.1540-6261.1970.tb00518.x

Farrell, J. (2014). Demographic and Socioeconomic Factors of Investors. In The Psychology of Financial Planning and Investing. Edited by $\mathrm{H}$. Kent Baker, Victor Ricciardi. (C) 2014 John Wiley \& Sons, Inc. Published 2014 by John Wiley \& Sons, Inc. (pp. 117-145). John Wiley \& Sons, Inc., Hoboken,. https://doi.org/https://doi.org/10.1002/9781118813454.ch7

Hassan, T. R., Khalid, W., \& Habib, A. (2014). Overconfidence and Loss Aversion in Investment Decisions: A Study of the Impact of Gender and Age in Pakistani Perspective. Research Journal of Finance and Accounting Www.liste.Org ISSN, 5(11), 148-158. www.iiste.org

Kahneman, A. T. and D. (1974). Judgment under uncertainty: Heuristics and biases. Science, 185, 1124-1131. https://doi.org/10.4324/9781912282562

Kahneman, B. Y. D., \& Tversky, A. (1979). Chapter 6. 47(2), 263-291.

Kumar, S., \& Goyal, N. (2015). Behavioural biases in investment decision making - a systematic literature review. Qualitative Research in Financial Markets, 7(1), 88-108. https://doi.org/10.1108/QRFM-072014-0022

Nana, A. (2012). HUBUNGAN FAKTOR DEMOGRAFI DENGAN BIAS PEMIKIRAN INVESTOR DI PASAR. Journal Business and Banking, 2(2). https://doi.org/http://dx.doi.org/10.14414/jbb.v2i2.169

Nofsinger, J. R. (2018). The Psychology of Investing. In The Psychology of Investing (Sixth Edit). Taylor and Francis. https://doi.org/10.4324/9781315506579

Nurvitasari, D., \& Rita, M. R. (2020). Confirmation Bias dalam Keputusan Investasi Dana Pensiun dengan Moderasi Gender Oleh: Jurnal Visi Manajemen Vol, 5(2), 758-776.

Park, J., Konana, P., Gu, B., Kumar, A., \& Raghunathan, R. (2012). 
Confirmation Bias, Overconfidence, and Investment Performance: Evidence from Stock Message Boards. In SSRN Electronic Journal (Issue October). https://doi.org/10.2139/ssrn.1639470

Pertiwi, P. J., Tommy, P., \& Tumiwa, J. R. (2016). Pengaruh Kebijakan Hutang, Keputusan Investasi Dan Profitabilitas Terhadap Nilai Perusahaan Food and Beverages Yang Terdaftar Di Bursa Efek Indonesia. Jurnal Riset Ekonomi, Manajemen, Bisnis Dan Akuntansi, $4((1))$.

Pompian, M. M. (2012). Behavioral Finance and Wealth Management. In Behavioral Finance and Wealth Management. https://doi.org/10.1002/9781119202400

Rahadjeng, E. R. (2011). Analisis Perilaku Investor Perspektif Gender Dalam Pengambilan Keputusan Investasi Di Pasar Modal. HUMANITY, Volume 6, Nomor 2, Maret 2011: 90 - 97Versi Online: Http://Ejournal.Umm.Ac.Id/Index.Php/Humanity/Article/View/1391, 6(2), 90-97.

Ritter, J. R. (2003). Behavioral finance. Pacific Basin Finance Journal, 11(4), 429-437. https://doi.org/10.1016/S0927-538X(03)00048-9

Skała, D. (2008). Overconfidence in Psychology and Finance - an Interdisciplinary Literature Review. Bank i Kredyt, nr 4, 33-50.

Sulistiawan, D. (2015). (2015). REAKSI ASIMETRI ATAS SINYAL BELI DAN JUAL ANALISIS TEKNIS: PENGUJIAN BIAS KONFIRMASI SEBELUM PENGUMUMAN LABA. Jurnal Keuangan Dan Perbankan, 19((3)), 400-408. https://doi.org/http://jurnal.unmer.ac.id/index.php/jkdp/article

Supramono, Supramono, Wandita, M. (2017). CONFIRMATION BIAS, SELF-ATTRIBUTION BIAS, DAN OVERCONFIDENCE DALAM TRANSAKSI SAHAM. Vol 21,(No 1).

Supramono, S., \& Wandita, M. (2017). Confirmation Bias, Self-Attribution Bias, Dan Overconfidence Dalam Transaksi Saham. Jurnal Keuangan Dan Perbankan, 21(1), 25-36. https://doi.org/10.26905/jkdp.v21i1.1224

Thi, L., \& Ngoc, B. (2014). Behavior Pattern of Individual Investors in Stock Market. 9(1), 1-16. https://doi.org/10.5539/ijbm.v9n1p1

Trejos, C., van Deemen, A., Rodríguez, Y. E., \& Gómez, J. M. (2019). Overconfidence and disposition effect in the stock market: A micro world based setting. Journal of Behavioral and Experimental Finance, 21, 61-69. https://doi.org/10.1016/j.jbef.2018.11.001

Waiqotul, J. (2017). ANALISIS FUNDAMENTAL, SUKU BUNGA, DAN OVERCONFIDENCE TERHADAP PENGAMBILAN KEPUTUSAN INVESTASI PADA INVESTOR DI SURABAYA. Ekspektra: Jurnal Bisnis Dan Manajemen, Vol 1,(No 2). https://doi.org/http://dx.doi.org/10.25139/ekt.v0i0.338.

Wulandari, D. A., \& Iramani, R. (2014). STUDI EXPERIENCED REGRET, RISK TOLERANCE, OVERCONFIDANCE DAN RISK PERCEPTION PADA PENGAMBILAN KEPUTUSAN INVESTASI. Journal of 
Business and Banking, Vol 4,(No 1), 55 - 66. https://doi.org/DOI: http://dx.doi.org/10.14414/jbb.v4i1.293 